\title{
Article \\ Reference Ranges of Left Ventricular Hemodynamic Forces in
Healthy Adults: A Speckle-Tracking Echocardiographic Study
}

\author{
Francesco Ferrara ${ }^{1}$, Francesco Capuano ${ }^{2}$, Rosangela Cocchia ${ }^{3}$, Brigida Ranieri ${ }^{4}\left(\mathbb{D}\right.$, Carla Contaldi ${ }^{5}$, \\ Graziella Lacava $^{6}$, Valentina Capone ${ }^{3}{ }^{-}$, Salvatore Chianese ${ }^{3}$, Salvatore Rega ${ }^{7}$, Roberto Annunziata ${ }^{3}{ }^{\circ}$, \\ Chiara Sepe ${ }^{3}$, Andrea Salzano ${ }^{4}\left(\mathbb{D}\right.$, Rodolfo Citro $\left.{ }^{1}{ }^{(}\right)$, Antonello $D^{\prime}$ Andrea ${ }^{8} \mathbb{C}$, Ciro Mauro ${ }^{3}$, \\ Filippo Cademartiri ${ }^{4}\left(\mathbb{D}\right.$, Gianni Pedrizzetti ${ }^{9}$ (D) and Eduardo Bossone ${ }^{3, *(\mathbb{D})}$
}

1 Cardio-Thoracic-Vascular Department, University Hospital "San Giovanni di Dio e Ruggi d'Aragona", 84125 Salerno, Italy; fferrara1975@gmail.com (F.F.); rodolfocitro@gmail.com (R.C.)

2 Department of Mechanics, Mathematics and Management, Polytechnic University of Bari, 70126 Bari, Italy; francesco.capuano@poliba.it

3 Cardiology Division, A Cardarelli Hospital, 80131 Naples, Italy; rosangela.cocchia@aocardarelli.it (R.C.); caponevalentina92@libero.it (V.C.); sasichian@gmail.com (S.C.); dr.robertoannunziata@gmail.com (R.A.); chiara.sepe@aocardarelli.it (C.S.); ciro.mauro1957@gmail.com (C.M.)

4 IRCCS SDN, 80143 Naples, Italy; brigida.ranieri@synlab.it (B.R.); andre.salzano@gmail.com (A.S.); filippocademartiri@gmail.com (F.C.)

check for updates

Citation: Ferrara, F.; Capuano, F.; Cocchia, R.; Ranieri, B.; Contaldi, C.; Lacava, G.; Capone, V.; Chianese, S.; Rega, S.; Annunziata, R.; et al. Reference Ranges of Left Ventricular Hemodynamic Forces in Healthy Adults: A Speckle-Tracking Echocardiographic Study. J. Clin. Med. 2021, 10, 5937. https://doi.org/ $10.3390 /$ jcm10245937

Academic Editors:

Arturo Evangelista,

Jose Rodríguez-Palomares and Marcus Dörr

Received: 4 October 2021

Accepted: 15 December 2021

Published: 17 December 2021

Publisher's Note: MDPI stays neutral with regard to jurisdictional claims in published maps and institutional affiliations.

Copyright: (C) 2021 by the authors Licensee MDPI, Basel, Switzerland. This article is an open access article distributed under the terms and conditions of the Creative Commons Attribution (CC BY) license (https:// creativecommons.org/licenses/by/ $4.0 /)$.
5 Heart Failure and Rehabilitative Cardiology Unit, AO dei Colli, Monaldi Hospital, 80131 Naples, Italy; contaldi.carla@gmail.com

6 Anesthesia and Intensive Care, University Hospital "San Giovanni di Dio e Ruggi d'Aragona", 84125 Salerno, Italy; graziellalacava1979@libero.it

7 Department of Translational Medical Sciences, Federico II University, 80131 Naples, Italy; salreg25@gmail.com

8 Unit of Cardiology, Department of Traslational Medical Sciences, University of Campania "Luigi Vanvitelli", Monaldi Hospital, 80131 Naples, Italy; antonellodandrea@libero.it

9 Department of Engineering and Architecture, University of Trieste, 34127 Trieste, Italy; giannip@dia.units.it

* Correspondence: eduardo.bossone@aocardarelli.it; Tel./Fax: +39-08-1747-3068

Abstract: Background: The normal limits of left ventricular (LV) hemodynamic forces (HDFs) are not exactly known. The aim of this study was to explore the full spectrum of HDF parameters in healthy subjects and determine their physiologic correlates. Methods: 269 healthy subjects were enrolled (mean age: $43 \pm 14$ years; 123 (45.7\%) men). All participants underwent an echo-Doppler examination. Tri-plane tissue tracking from apical views was used to measure $2 \mathrm{D}$ global endocardial longitudinal strain (GLS), circumferential strain (GCS), and LV HDFs. HDFs were normalized with LV volume and divided by specific weight. Results: LV systolic longitudinal HDFs (\%) were higher in men $(20.8 \pm 6.5$ vs. $18.9 \pm 5.6, p=0.009 ; 22.0 \pm 6.7$ vs. $19.8 \pm 5.6, p=0.004$, respectively). There was a significant correlation between GCS (increased) $(\mathrm{r}=-0.240, p<0.001)$ and LV longitudinal HDFs (reduced) $(\mathrm{r}=-0.155, p=0.01)$ with age. In a multivariable analysis age, BSA, pulse pressure, heart rate and GCS were the only independent variables associated with LV HDFs ( $\beta$ coefficient $=-0.232$, $p<0.001 ; 0.149, p=0.003 ; 0.186, p<0.001 ; 0.396, p<0.001 ;-0.328, p<0.001$; respectively). Conclusion: We report on the physiologic range of LV HDFs. Knowledge of reference values of HDFs may prompt their implementation into clinical routine and allow a more comprehensive assessment of the LV function.

Keywords: speckle-tracking echocardiography; hemodynamic forces; intraventricular pressure gradient; left ventricle; strain

\section{Introduction}

Left ventricular (LV) function is a major diagnostic and prognostic determinant of a wide range of cardiac diseases [1-3]. The LV ejection fraction (EF) is the most commonly used parameter to evaluate LV function, although it only provides global information about 
the chamber contraction. In this regard, the development and clinical implementation of speckle-tracking echocardiography (STE) have allowed the study of the regional myocardial deformation by global longitudinal strain (GLS) and global circumferential strain (GCS) indices to be more effective in detecting subclinical alteration of LV function compared to LV EF [4-9]. Furthermore, advances in post-processing of standard STE technology have permitted to estimate the intraventricular pressure gradients (IVPG), that drive blood flow during LV ejection and filling [10-12]. This has led to the definition of the LV hemodynamic forces (HDFs) as IVPG averaged over the LV volume, reflecting the forces effectively exchanged between the blood flow and the LV walls $[13,14]$. HDFs were proposed as an indicator of the correct sequence of IVPGs generation and thus of LV pumping function [15]. Recent studies have demonstrated that parameters based on HDF compared to LV EF and strain may provide additional information about structural and functional LV adaptations, representing promising markers for the identification of silent sub-clinical myocardial dysfunction [16-20]. Interestingly, innovative mathematical developments demonstrated that the HDFs in the LV can be computed exactly through a proper post-processing of results of standard STE [21,22]. However, the normal limits and physiologic correlates of LV HDFs have not been fully investigated [20-22]. Therefore, the aim of this study was to explore the full range of LV HDFs indices along with clinical and echocardiographic correlates in a large cohort of healthy subjects.

\section{Methods}

\subsection{Study Population}

The study population consisted of 269 healthy subjects (volunteers or subjects referred for work ability assessment; mean age $43.4 \pm 14.0$; 123 (45.7\%) men) [23,24]. They underwent, at the echocardiographic laboratory of the Cardiology Division, "Cava de'TirreniAmalfi Coast", Heart Department, University Hospital of Salerno, full screening for cardiovascular disease, including a questionnaire on medical history, use of medications, cardiovascular risk factors and lifestyle habits (alcohol intake, smoking, physical activity) $[23,24]$. Physical examinations (height, weight, heart rate (HR) and blood pressure (BP)) and clinical assessments were conducted according to standardized protocols by trained and certified staff $[23,24]$. Body surface area (BSA) was calculated according to the DuBois formula $(0.20247 \times$ height $(\mathrm{m}) 0.725 \times$ weight $(\mathrm{kg}) 0.425)$. Three BP measurements were obtained from the right arm by sphygmomanometer and the results were averaged to determine systolic and diastolic BP. Pulse pressure (PP) was calculated as systolic BP (SBP)-diastolic BP (DBP). The study was approved by the institution's ethics board and informed consent was obtained from all participants [23,24].

\subsection{Conventional Echocardiography}

Transthoracic echocardiography (TTE) examinations were performed with commercially available equipment on all subjects (Vivid E9-GE Healthcare, Milwaukee, WI, USA). Two independent experienced operators (FF, RC), blinded to the clinical data, performed offline left and right heart measurements and speckle-tracking (ST) analysis according to the current recommendations of the American Society of Echocardiography/European Association of Cardiovascular Imaging [25-27]. Specific views included the parasternal long- and short-axis views, apical 4, 2 and 3 chamber views and subcostal views, including respiratory collapse of the inferior vena cava (IVC). Pulsed and continuous wave Doppler interrogation was performed on all 4 cardiac valves. Specific average measurements were taken of the 5 cardiac cycles. M-mode measurements were performed in the parasternal long-axis view with the patient in the left lateral position and included left ventricular internal diameter in diastole (LVIDd) and systole (LVIDs), the interventricular septum in diastole (IVSDd) and the inferolateral wall in diastole (ILWTDd). LV mass was calculated by the Penn convention and indexed for BSA [25]. The LV EF was calculated from LV end-diastolic and end-systolic volumes by modified Simpson's equation in the apical 4 and 2 chamber views [25]. Valvular regurgitation was quantified from color Doppler 
imaging and categorized as absent, minimal (within normal limits), mild, moderate or severe [25]. Doppler-derived LV diastolic inflow was recorded in the apical 4-chamber view by placing the sample volume at the tip of the mitral valve leaflets. The following LV diastolic parameters were measured: $E$ and A peak velocities $(\mathrm{m} / \mathrm{s})$ and their ratio and $\mathrm{E}$ wave deceleration time (ms). The early $\left(\mathrm{e}^{\prime}\right)$ diastolic velocities were measured by tissue Doppler imaging (TDI) at the septal and lateral corner of the mitral annulus and the mean between the two values was calculated. Mitral E velocity, corrected for the influence of relaxation (i.e., the $\mathrm{E} / \mathrm{mean}^{\prime}$ ratio), was assessed to estimate $\mathrm{LV}$ filling pressures [26]. LV stroke volume (SV) was calculated as the product of LV outflow tract area and outflow tract velocity time integral (VTI). Cardiac output (CO) was calculated using the following formula: $\mathrm{CO}(\mathrm{L} / \mathrm{min})=\mathrm{HR} \times \mathrm{LV} \mathrm{SV}$ [23-25].

\subsection{Speckle-Tracking Analysis}

We included healthy subjects with frame rate acquisition of at least $50 \mathrm{~Hz}$ and with optimal images of all 18 segments in order to conduct strain-based HDFs analysis. In this regard, 37 subjects were excluded due to poor imaging quality (total study population $=269$ ). 2D images from apical views (4-, 3- and 2-chamber) were re-analyzed offline using a commercially available software (2D-CPA v.1.4; TomTec Imaging Systems Gmbh, Unterschleissheim, Germany). The cardiac cycle was selected where the endocardial borders were better visible both in diastole and in systole. The LV end-systolic endocardial borders in each apical view were drawn and the software tracked the endocardial borders over the entire heartbeat. When necessary, the end-diastolic borders were corrected manually with consequent automatic propagation of the border correction over the entire cycle to match the original end-systolic borders. The LV end-systolic and end-diastolic volumes were calculated according to the modified Simpson rule $[4,25,28]$. Speckle-tracking analysis was performed to obtain 2D global longitudinal strain (GLS) and global circumferential strain (GCS), including 6 segments in each of the 3 apical views (4-, 3- and 2-chamber). Segments in which no adequate tracking quality could not be obtained despite manual adjustment being excluded. The 2D GLS and GCS were calculated as the average of 18 myocardial segments recorded in the three apical views [4,28] (Figure 1). The end-systolic GLS and GCS was then extracted as the main deformation parameter.

\subsection{Hemodynamic Forces}

HDFs were originally computed from the blood velocity in the LV volume [15-17]. A recent mathematical formulation, based on the balance of momentum, demonstrated that the same quantity can also be evaluated from the motion of the endocardium and by the average flow across the mitral valve and outlet tract [22]. The mitral diameter was evaluated by the average in the three images view at end-diastole, measuring the internal edge of the valve annulus: (a) parasternal long-axis view (anterior-posterior diameter); (b) apical four-chamber view; and (c) apical two-chamber view. The aortic diameter was measured at peak systole in the 3-chamber projection from the inner edge of the valve. This formulation was included in a prototype version of the previously mentioned software for STE; an analogous prototype was previously used with feature tracking in cine magnetic resonance imaging (MRI) [19].

From the three endocardial borders estimated by speckle-tracking during the cardiac cycle, and from the knowledge of the aortic root and mitral inflow dimensions, the strain software also computed the time profile of the longitudinal (apex-base, $\mathrm{HDF}_{\mathrm{L}}$ ) and transversal (inferolateral-anteroseptal, $\mathrm{HDF}_{\mathrm{T}}$ ) components of HDFs. To improve comparability between different subjects, forces were expressed in dimensionless form after normalization with the LV volume and specific weight, and expressed as a percentage of gravity acceleration. A typical time evolution of the HDF components over the cardiac cycle is illustrated in Figure 2, superimposed with the LV volume. 

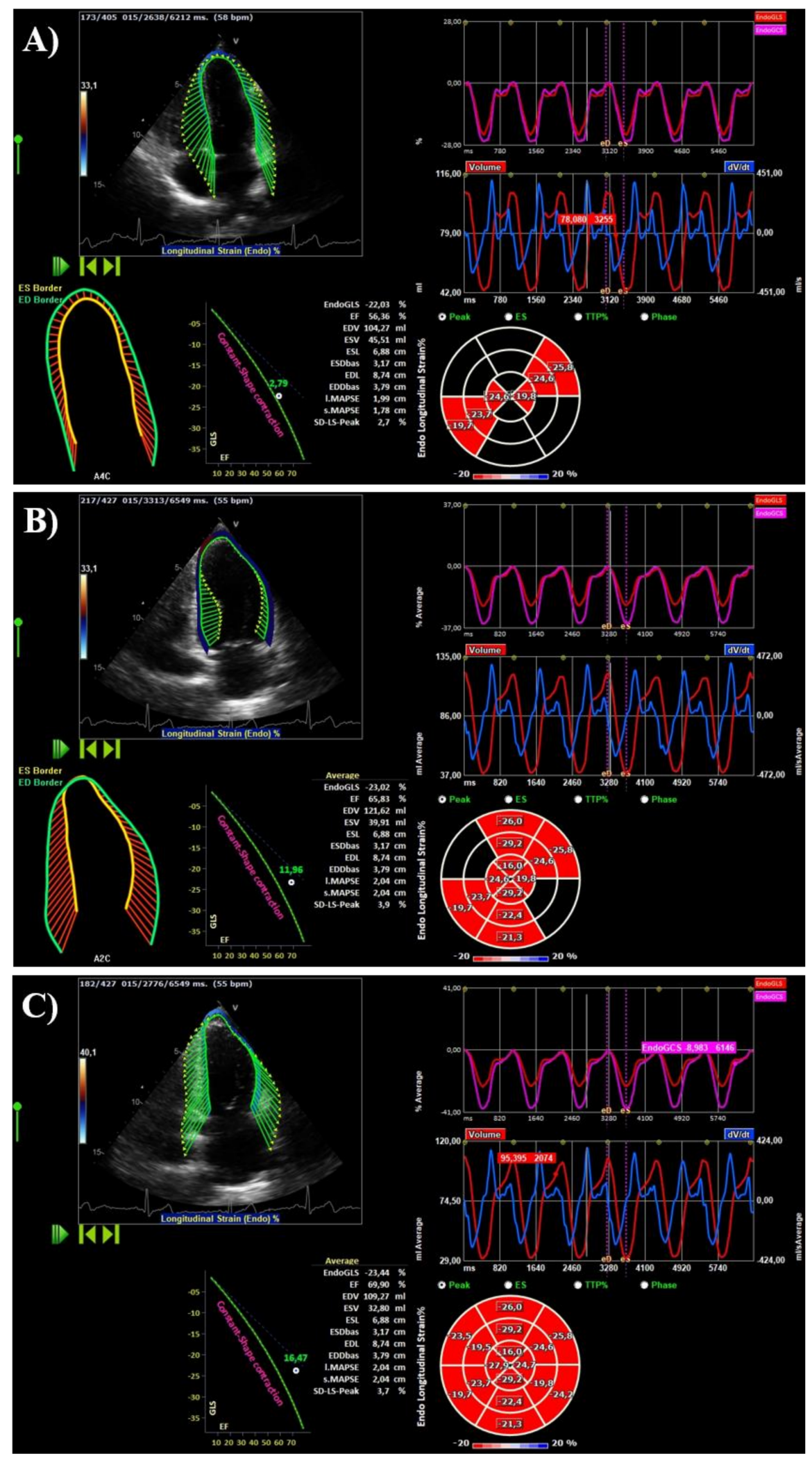

Figure 1. Post processing steps. (A) Analysis of apical 4 chamber view with vector velocity imaging, representation of endo GCS and GLS, variation of volumes and $\mathrm{dV} / \mathrm{dt}$, segmental longitudinal strain showed as bull-eye. (B) Analysis of 2 chamber view. (C) Analysis of 3 chamber view with average data. GCS, global circumferential strain; GLS, global longitudinal strain. 


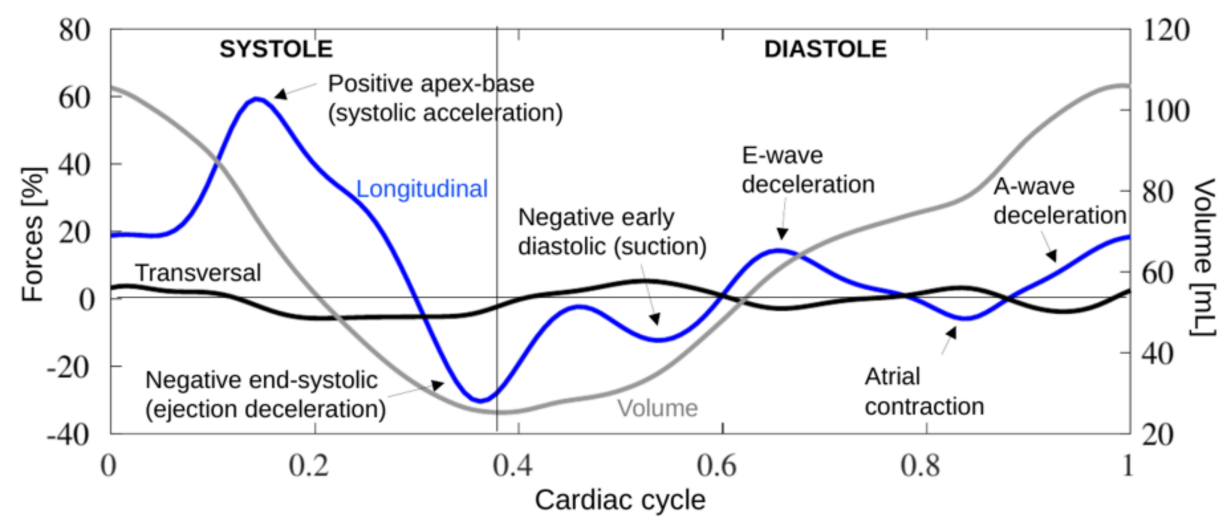

Figure 2. Typical time evolution of left ventricular hemodynamic forces over the cardiac cycle. The blue line shows apical-basal LV longitudinal forces, larger positive compared with transversal components (black line). Acceleration toward the base accounts for the systolic peak acceleration, after which deceleration causes the late systolic negative peak. Coinciding with the onset of diastole, another small negative early peak (suction) appeared, corresponding to early passive filling of the left ventricle (E-wave). A similar pattern was seen toward the end of diastole, corresponding to atrial contraction (A-wave). The grey line shows the LV volume over the cardiac cycle.

From the time-profile, some physically-based parameters were extracted for numerical comparisons. The HDF parameters were: (a) the systolic impulse, computed as the area under the curve of the longitudinal force during the positive interval of the systolic phase [29], this value was normalized with the time interval thus providing the systolic time average; (b) the systolic peak of the longitudinal force during the systolic phase; (c) the average amplitude, computed as the root mean square (rms) of both components (longitudinal and transversal) over the whole cardiac cycle; (d) the average amplitude during systole only and; (e) during diastole; (f) the alignment of the force with the LV axis, an angle ranging from $0^{\circ}$ (perfect longitudinal alignment) to $90^{\circ}$ (completely transversal) computed by the average angle during the cardiac cycle [7]. The calculation of the parameters of the LV HDF was performed using a commercially available software (2D-CPA v.1.4; TomTec Imaging Systems Gmbh, Unterschleissheim, Germany) (Figure 3).

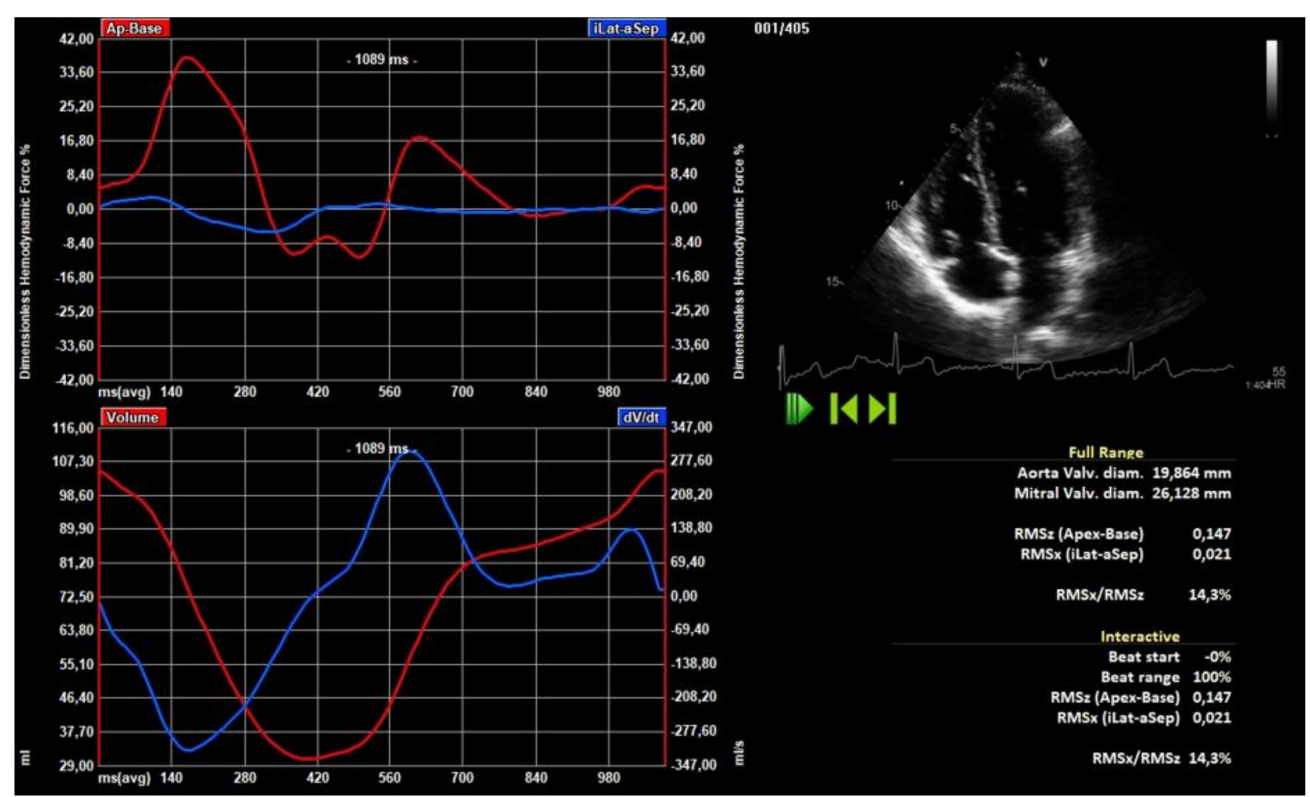

Figure 3. Representation of dimensionless hemodynamic forces obtained by speckle tracking analysis. 


\subsection{Statistical Analysis}

Continuous variables were expressed as means \pm standard deviation (SD). Normal distribution of the continuous values was assessed by the Kolmogorov-Smirnov test. Differences between groups were analyzed by unpaired Student $t$-test. $p$-values less than 0.05 were considered as statistically significant. As lower and upper limits for normal HDFs, we used $95 \%$ confidence intervals (CI) and/or \pm 2 SD. The Pearson's correlation analysis was used to determine correlations between continuous variables. The variables were selected according to their clinical relevance and potential impact on LV HDFs. Multivariable linear regression analysis, including all significant clinical and echocardiographic parameters from the univariate analysis was constructed to assess the independent associations of these variables with LV HDFs. We reported the standardized beta coefficients in regression analysis. The inter- and intra-observer variabilities were examined using both paired $t$-tests and intraclass correlation coefficient (ICC) in 30 randomly selected cases. An ICC of $>0.8$ indicated good agreement. Data were processed using MATLAB ${ }^{\circledR}$ (Mathworks, Natick, MA, USA).

\section{Results}

\subsection{Demographic Data}

The demographic data of the study population are reported in Table 1. A total of 123 men (mean age $43 \pm 14$ years) and 146 women (mean age $44 \pm 14$ years) were included. Compared with men, women had a lower height and weight, lower BSA and body mass index (BMI), lower BP and higher HR.

Table 1. Demographic and clinical characteristics of study population.

\begin{tabular}{ccccc}
\hline Variable & Overall & Women & Men & $p$ Value \\
\hline & $(\boldsymbol{n}=\mathbf{2 6 9 )}$ & $(\boldsymbol{n}=\mathbf{1 4 6})$ & $(\boldsymbol{n}=\mathbf{1 2 3})$ & \\
\hline & $\mathbf{( M e a n} \pm \mathbf{S D )}$ & $\mathbf{( M e a n} \pm \mathbf{S D )}$ & $\mathbf{( M e a n} \pm \mathbf{S D )}$ & \\
\hline Age (years) & $43.4 \pm 14.0$ & $43.7 \pm 13.9$ & $43.1 \pm 14.1$ & 0.7 \\
\hline Height $(\mathrm{cm})$ & $168 \pm 9$ & $162 \pm 7$ & $175 \pm 7$ & $<0.001$ \\
\hline Weight $(\mathrm{kg})$ & $70 \pm 12$ & $63 \pm 9$ & $78 \pm 10$ & $<0.001$ \\
\hline BMI $\left(\mathrm{kg} / \mathrm{m}^{2}\right)$ & $24.6 \pm 3.1$ & $24.0 \pm 3.1$ & $25.4 \pm 2.9$ & $<0.001$ \\
\hline BSA $\left(\mathrm{m}^{2}\right)$ & $1.78 \pm 0.19$ & $1.67 \pm 0.14$ & $1.91 \pm 0.16$ & $<0.001$ \\
\hline Systolic BP $\left(\mathrm{mmHg}^{2}\right)$ & $122 \pm 12$ & $120 \pm 13$ & $124 \pm 11$ & $<0.001$ \\
\hline Diastolic BP $(\mathrm{mmHg})$ & $77 \pm 8$ & $75 \pm 9$ & $78 \pm 8$ & 0.007 \\
\hline Mean BP $(\mathrm{mmHg})$ & $92 \pm 9$ & $90 \pm 9$ & $93 \pm 8$ & 0.002 \\
\hline Pulse pressure $(\mathrm{mmHg})$ & $45 \pm 10$ & $44 \pm 10$ & $45 \pm 9$ & 0.167 \\
\hline HR $(\mathrm{b} / \mathrm{m})$ & $73 \pm 12$ & $74 \pm 12$ & $71 \pm 12$ & 0.018 \\
\hline
\end{tabular}

BMI, body mass index; BP, blood pressure; BSA, body surface area; HR, heart rate; $p$ values indicate sex-related differences.

\subsection{Left Heart Echo-Doppler Analysis}

Women had smaller LV wall thicknesses, LV dimensions, LV mass, left atrial volume and LV volume (all $p<0.001$ ). On the other hand, compared to women, men had slightly higher LV ejection fraction $(p=0.049)$. No significant sex-related differences in mitral peak $\mathrm{E} / \mathrm{e}^{\prime}$ ratio were noted $(p=0.319)$. However, men demonstrated higher $\mathrm{SV}(p<0.001)$ and $\mathrm{CO}(p=0.005)$ (Table 2$)$. 
Table 2. Left heart structure and function in study population.

\begin{tabular}{|c|c|c|c|c|}
\hline Variable & Overall & Women & Men & $p$ Value \\
\hline & $(n=269)$ & $(n=146)$ & $(n=123)$ & \\
\hline & $($ Mean \pm SD) & $($ Mean \pm SD) & $($ Mean \pm SD) & \\
\hline $\begin{array}{l}\text { Septal wall thickness in } \\
\text { diastole }(\mathrm{mm})\end{array}$ & $8.9 \pm 1.4$ & $8.3 \pm 1.3$ & $9.6 \pm 1.2$ & $<0.001$ \\
\hline $\begin{array}{c}\text { Inferolateral wall } \\
\text { thickness }(\mathrm{mm}) \text { diastole }\end{array}$ & $8.9 \pm 1.4$ & $8.4 \pm 1.5$ & $9.6 \pm 1.3$ & $<0.001$ \\
\hline $\begin{array}{l}\text { LV end-diastolic } \\
\text { diameter }(\mathrm{mm})\end{array}$ & $45.0 \pm 4.0$ & $43.4 \pm 3.6$ & $46.9 \pm 3.7$ & $<0.001$ \\
\hline $\begin{array}{c}\text { Proximal ascending } \\
\text { aorta }(\mathrm{mm})\end{array}$ & $28.9 \pm 3.1$ & $27.8 \pm 2.9$ & $30.3 \pm 2.8$ & $<0.001$ \\
\hline $\mathrm{LV}$ mass/BSA $\left(\mathrm{g} / \mathrm{m}^{2}\right)$ & $85.6 \pm 20.2$ & $77.5 \pm 17.4$ & $95.4 \pm 19.1$ & $<0.001$ \\
\hline LA Volume (mL) & $32.5 \pm 7.1$ & $31.0 \pm 6.7$ & $34.4 \pm 7.0$ & $<0.001$ \\
\hline LV EDV (mL) & $99 \pm 21$ & $88 \pm 15$ & $113 \pm 21$ & $<0.001$ \\
\hline LV ESV (mL) & $37 \pm 10$ & $32 \pm 8$ & $42 \pm 9$ & $<0.001$ \\
\hline LV EF (biplane) (\%) & $64.2 \pm 5$ & $63.7 \pm 4.4$ & $64.9 \pm 5.6$ & 0.049 \\
\hline Mitral Peak E/e' ratio & $5.6 \pm 1.5$ & $5.7 \pm 1.5$ & $5.5 \pm 1.4$ & 0.319 \\
\hline $\mathrm{SV}(\mathrm{mL})$ & $64 \pm 13$ & $60.0 \pm 11.6$ & $68.5 \pm 12.6$ & $<0.001$ \\
\hline $\mathrm{CO}(\mathrm{L} / \mathrm{min})$ & $4.6 \pm 1.1$ & $4.4 \pm 1.0$ & $4.8 \pm 1.1$ & 0.005 \\
\hline
\end{tabular}

BSA, body surface area; CO, cardiac output; E, mitral early inflow velocity; $\mathrm{e}^{\prime}$, early diastolic mitral annular lateral velocity; EDV, end-diastolic volume; EF, ejection fraction; ESV, end-systolic volume; LA, left atrium; LV, left ventricular; $\mathrm{SD}$, standard deviation; SV, stroke volume indexed; $p$ values indicate sex-related differences.

\subsection{Right Heart Echo-Doppler Analysis}

Right heart dimensions were larger in men (all $p<0.001)$. No significant sex-related differences in tricuspid annular plane systolic excursion (TAPSE) $(p=0.916), \mathrm{S}^{\prime}(p=0.251)$ and pulmonary artery systolic pressure $(p=0.170)$ were found. Compared to women, men had slightly shorter right ventricular outflow tract (RVOT) acceleration time (Act) $(p=0.049)$ (Table 3).

Table 3. Structural and functional variables of the right heart and pulmonary circulation in the study population.

\begin{tabular}{ccccc}
\hline Variable & Overall & Women & Men & $p$ Value \\
\hline & $(\boldsymbol{n}=\mathbf{2 6 9 )}$ & $(\boldsymbol{n}=\mathbf{1 4 6 )}$ & $\mathbf{( n = 1 2 3 )}$ & \\
\hline & $\mathbf{( M e a n} \pm \mathbf{S D})$ & $\mathbf{( M e a n} \pm \mathbf{S D )}$ & $\mathbf{( M e a n} \pm \mathbf{S D )}$ & \\
\hline RV basal diameter $(\mathrm{mm})$ & $34.6 \pm 2.9$ & $33.5 \pm 2.8$ & $35.8 \pm 2.4$ & $<0.001$ \\
\hline $\begin{array}{c}\text { RV longitudinal } \\
\text { diameter }(\mathrm{mm})\end{array}$ & $62.7 \pm 6.1$ & $60.6 \pm 6.2$ & $65.2 \pm 6.1$ & $<0.001$ \\
\hline RA Volume $(\mathrm{mL})$ & $28.8 \pm 7.9$ & $26.0 \pm 5.8$ & $32.1 \pm 8.8$ & $<0.001$ \\
\hline TAPSE $(\mathrm{mm})$ & $22.7 \pm 2.4$ & $22.7 \pm 2.4$ & $22.7 \pm 2.4$ & 0.916 \\
\hline S' $(\mathrm{cm} / \mathrm{s})$ & $13.5 \pm 2.2$ & $13.4 \pm 2.0$ & $13.7 \pm 2.3$ & 0.251 \\
\hline PASP $(\mathrm{mmHg})$ & $21.8 \pm 4.8$ & $21.5 \pm 4.4$ & $22.3 \pm 5.3$ & 0.170 \\
\hline RVOT AcT $(\mathrm{ms})$ & $136.9 \pm 18.3$ & $139.8 \pm 18.2$ & $134.5 \pm 18.2$ & 0.049
\end{tabular}

AcT, acceleration time; PASP, pulmonary artery systolic pressure; RA, right atrial; RV, right ventricular; RVOT, right ventricular outflow tract; $S^{\prime}$, tissue Doppler-derived tricuspid lateral annular systolic velocity; TAPSE, tricuspid annular plane systolic excursion; $p$ values indicate sex-related differences. 


\subsection{Deformation}

The values of end-systolic global LV strain for the overall population were GLS $=-23.1 \pm 1.5$ and GCS $=-33.0 \pm 3.9$. No significant sex-related differences of the mean values of GLS and GCS were found ( $p=$ not significant (ns)) (Table 4).

Table 4. Endocardial strain parameters in study population.

\begin{tabular}{|c|c|c|c|c|}
\hline Variable & Overall & Women & Men & $p$ Value \\
\hline & $(n=269)$ & $(n=146)$ & $(n=123)$ & \\
\hline & Mean \pm SD & Mean \pm SD & Mean \pm SD & \\
\hline & $(95 \% \mathrm{CI})$ & $(95 \% \mathrm{CI})$ & $(95 \% \mathrm{CI})$ & \\
\hline GLS, \% & $\begin{array}{c}-23.1 \pm 1.5 \\
(-20.1 \text { to }-26.1)\end{array}$ & $\begin{array}{c}-23.1 \pm 1.5 \\
(-20.1 \text { to }-26.1)\end{array}$ & $\begin{array}{c}-23.1 \pm 1.5 \\
(-20.1 \text { to }-26.1)\end{array}$ & 1.0 \\
\hline GCS, \% & $\begin{array}{c}-33.0 \pm 3.9 \\
(-25.3 \text { to }-40.1)\end{array}$ & $\begin{array}{c}-33.1 \pm 3.9 \\
(-25.4 \text { to }-40.8)\end{array}$ & $\begin{array}{c}-32.8 \pm 3.8 \\
(-25.3 \text { to }-40.3)\end{array}$ & 0.4 \\
\hline
\end{tabular}

CI, confidence interval; GCS, global circumferential strain; GLS, global longitudinal strain; $p$ values indicate sex-related differences; $\mathrm{SD}$, standard deviation.

\subsection{Hemodynamic Forces}

The mean values of HDFs parameters of the overall population were: (a) systolic impulse $=19.8 \% \pm 6.1$, with (b) average amplitude of the longitudinal component in the entire heartbeat $=15.0 \% \pm 4.4$, that was higher during systole $=20.8 \% \pm 6.2$ and lower during diastole $=8.1 \% \pm 2.7$. LV systolic impulse $(\%)$ and LV systolic longitudinal force $(\%)$ were higher in men $(20.8 \pm 6.5$ vs. $18.9 \pm 5.6, p=0.009 ; 22.0 \pm 6.7$ vs. $19.8 \pm 5.6$, $p=0.004$, respectively). The lower limits of normal of the longitudinal force in the whole cycle were $6.3 \%$ in men and $6.5 \%$ in women. Systolic longitudinal force was $8.8 \%$ in both sexes. The amplitude values were lower for the transversal component. LV transversal force $(\%)$ during the whole cycle and systole was higher in men $(2.6 \pm 1.0$ vs. $2.2 \pm 0.8$, $p=0.004 ; 2.9 \pm 1.1$ vs. $2.5 \pm 0.9, p<0.001$, respectively). The lower limits of normal of the transversal HDFs in the whole cycle and during systole were $0.6 \%$ and $0.7 \%$ in both sexes, respectively. No significant sex-related differences during diastole for longitudinal and transversal components were noted ( $p$ value $=n s)$. On average, the force showed a good alignment of $14^{\circ} \pm 3.6$ with the LV axis, slightly greater in women (Table 5).

Table 5. Hemodynamic forces parameters in study population.

\begin{tabular}{|c|c|c|c|c|}
\hline Variable & Overall & Women & Men & $p$ Value \\
\hline & $(n=269)$ & $(n=146)$ & $(n=123)$ & \\
\hline & $($ Mean \pm SD) & $($ Mean \pm SD) & $($ Mean \pm SD) & \\
\hline & $(95 \% \mathrm{CI})$ & $(95 \% \mathrm{CI})$ & $(95 \% \mathrm{CI})$ & \\
\hline \multicolumn{5}{|l|}{ Longitudinal force, FL } \\
\hline Whole cycle, \% & $\begin{array}{c}15.0 \pm 4.4 \\
(6.3 \text { to } 23.7)\end{array}$ & $\begin{array}{c}14.6 \pm 4.1 \\
(6.5 \text { to } 22.7)\end{array}$ & $\begin{array}{c}15.6 \pm 4.7 \\
(6.3 \text { to } 24.9)\end{array}$ & 0.06 \\
\hline Systolic impulse, $\%$ & $\begin{array}{c}19.8 \pm 6.1 \\
(7.8 \text { to } 31.8)\end{array}$ & $\begin{array}{c}18.9 \pm 5.6 \\
(7.9 \text { to } 29.9)\end{array}$ & $\begin{array}{c}20.8 \pm 6.5 \\
(8.0 \text { to } 33.6)\end{array}$ & 0.009 \\
\hline Systolic, \% & $\begin{array}{c}20.8 \pm 6.2 \\
(8.6 \text { to } 33.0)\end{array}$ & $\begin{array}{c}19.8 \pm 5.6 \\
(8.8 \text { to } 30.8)\end{array}$ & $\begin{array}{c}22.0 \pm 6.7 \\
(8.8 \text { to } 35.2)\end{array}$ & 0.004 \\
\hline Diastolic, \% & $\begin{array}{c}8.1 \pm 2.7 \\
(2.8 \text { to } 13.4)\end{array}$ & $\begin{array}{c}8.1 \pm 2.8 \\
(2.6 \text { to } 13.6)\end{array}$ & $\begin{array}{c}8.1 \pm 2.6 \\
(3.0 \text { to } 13.2)\end{array}$ & 0.9 \\
\hline
\end{tabular}


Table 5. Cont.

\begin{tabular}{|c|c|c|c|c|}
\hline Variable & Overall & Women & Men & $p$ Value \\
\hline & $(n=269)$ & $(n=146)$ & $(n=123)$ & \\
\hline & $($ Mean \pm SD) & $($ Mean \pm SD) & $($ Mean \pm SD) & \\
\hline & $(95 \% \mathrm{CI})$ & $(95 \% \mathrm{CI})$ & $(95 \%$ CI $)$ & \\
\hline \multicolumn{5}{|l|}{ Transversal force, FT } \\
\hline Whole cycle, $\%$ & $\begin{array}{c}2.4 \pm 0.9 \\
(0.6 \text { to } 4.2)\end{array}$ & $\begin{array}{c}2.2 \pm 0.8 \\
(0.6 \text { to } 3.8)\end{array}$ & $\begin{array}{c}2.6 \pm 1.0 \\
(0.6 \text { to } 4.6)\end{array}$ & 0.004 \\
\hline Systolic, \% & $\begin{array}{c}2.7 \pm 1.0 \\
(0.7 \text { to } 4.7)\end{array}$ & $\begin{array}{c}2.5 \pm 0.9 \\
(0.7 \text { to } 4.3)\end{array}$ & $\begin{array}{c}2.9 \pm 1.1 \\
(0.7 \text { to } 5.1)\end{array}$ & $<0.001$ \\
\hline Diastolic, \% & $\begin{array}{c}2.1 \pm 1.1 \\
(0.0 \text { to } 3.3)\end{array}$ & $\begin{array}{c}2.0 \pm 1.0 \\
(0.0 \text { to } 4.0)\end{array}$ & $\begin{array}{c}2.2 \pm 1.1 \\
(0.0 \text { to } 4.4)\end{array}$ & 0.1 \\
\hline Alignment angle, ${ }^{\circ}$ & $\begin{array}{c}14.0 \pm 3.6 \\
(6.9 \text { to } 21.1)\end{array}$ & $\begin{array}{c}13.5 \pm 3.3 \\
(7.0 \text { to } 20.0)\end{array}$ & $\begin{array}{c}14.7 \pm 3.3 \\
(8.2 \text { to } 21.2)\end{array}$ & 0.004 \\
\hline
\end{tabular}

$p$ values indicate sex-related differences.

\subsection{Clinical and Echocardiographic Correlates of LV Hemodynamic Force}

No significant correlation between left ventricular ejection fraction (LVEF) and GLS with age was found $(\mathrm{r}=-0.022$ and $\mathrm{r}=-0.039$, respectively, all $p=\mathrm{ns})$. GCS showed a statistically significant correlation with age $(\mathrm{r}=-0.240 ; p<0.001)$ (Figure 4$)$.

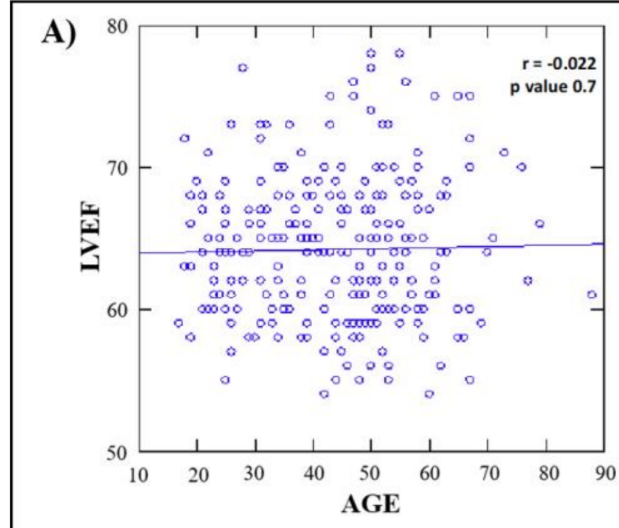

C)

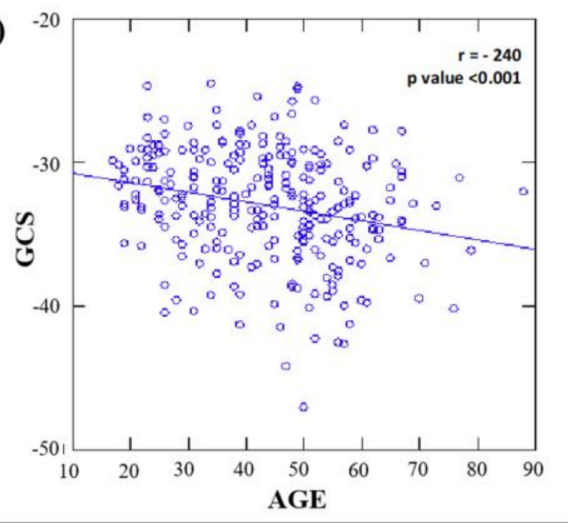

B)

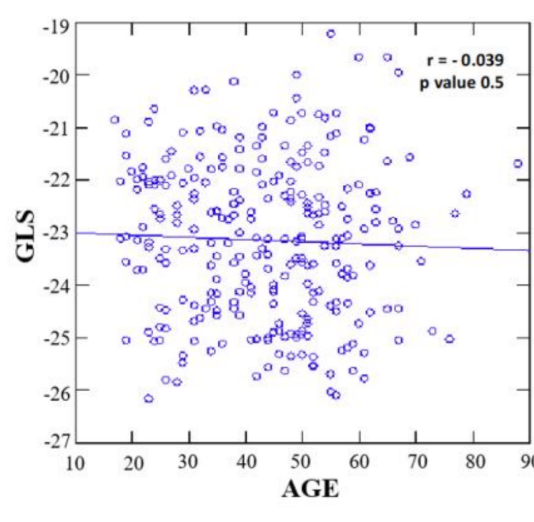

D)

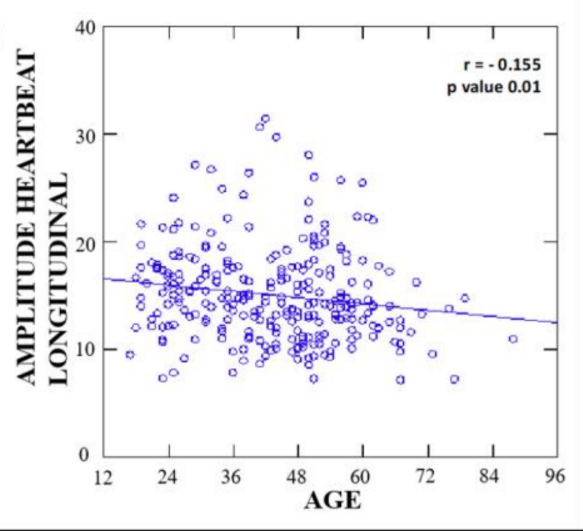

Figure 4. LVEF (A); GLS (B); GCS (C); amplitude heart beat longitudinal and (D) hemodynamic forces plotted against age in overall population. LVEF, left ventricular ejection fraction; GLS, global longitudinal strain; GCS, global circumferential strain. 
In univariate analysis, LV longitudinal HDF was negatively correlated with age $(\mathrm{r}=-0.155, p=0.01)$, BSA $(\mathrm{r}=0.390 ; p=0.02)$, pulse pressure $(\mathrm{r}=0.206 ; p=0.001)$ and heart rate $(\mathrm{r}=0.480 ; p<0.001)$. Furthermore, LV longitudinal force was weakly correlated with GLS ( $\mathrm{r}=-0.153 ; p=0.01)$ and more significantly with GCS ( $\mathrm{r}=-0.254 ; p<0.001)$. On the opposite, no significant correlation between LV longitudinal HDFs and LV mass, LA volume, LVEF (\%), stroke volume and E/e' was found (all $p=\mathrm{ns}$ ) (Table 6).

Table 6. Significant independent relation of left ventricular hemodynamic forces in the overall population with clinical and echocardiographic variables by univariate and multivariate analysis.

\begin{tabular}{|c|c|c|c|c|c|}
\hline \multirow{2}{*}{$\begin{array}{l}\text { Variables Related with Amplitude } \\
\text { Heart-Beat Longitudinal }\end{array}$} & \multicolumn{3}{|c|}{ Univariate Analysis } & \multicolumn{2}{|c|}{ Multivariate Analysis } \\
\hline & $r$ & $95 \% \mathrm{CI}$ & $p$ Value & Std Coefficient $(\beta)$ & $p$ Value \\
\hline Gender & -0.114 & -0.230 to 0.006 & 0.6 & & \\
\hline Age (years) & -0.155 & -0.270 to -0.036 & 0.01 & -0.232 & $<0.001$ \\
\hline $\operatorname{BSA}\left(\mathrm{m}^{2}\right)$ & 0.139 & 0.019 to 0.254 & 0.02 & 0.149 & 0.003 \\
\hline Pulse pressure (mmHg) & 0.206 & 0.089 to 0.319 & 0.001 & 0.186 & $<0.001$ \\
\hline Heart rate (bpm) & 0.448 & 0.346 to 0.539 & $<0.001$ & 0.396 & $<0.001$ \\
\hline LV mass (gr) & 0.076 & -0.044 to 0.195 & 0.21 & & \\
\hline LA vol (mL) & 0.011 & -0.109 to 0.131 & 0.86 & & \\
\hline LV EF (\%) & 0.120 & 0.000 to 0.237 & 0.05 & & \\
\hline LV SV (mL) & -0.095 & -0.213 to 0.025 & 0.121 & & \\
\hline $\mathrm{E} / \mathrm{e}^{\prime}$ & -0.119 & -0.044 to 0.195 & 0.052 & & \\
\hline GLS & -0.153 & -0.268 to -0.034 & 0.01 & -0.056 & 0.266 \\
\hline GCS & -0.254 & -0.390 to -0.170 & $<0.001$ & -0.328 & $<0.001$ \\
\hline
\end{tabular}

BSA, body surface area; CI, confidence interval; EF, ejection fraction; GLS, global longitudinal strain; GCS, global circumferential strain; LA, left atrial; LV, left ventricular; SV, stroke volume. The partial correlation test by the Pearson method was used to assess clinically relevant variables with $p<0.05$, which were then incorporated into the multivariate model assessed by multiple linear regression analysis.

In a multivariable analysis age, BSA, pulse pressure, heart rate and GCS were the only independent variables associated with LV longitudinal HDFs $(\beta$ coefficient $=-0.232$, $p<0.001 ; 0.149, p=0.003 ; 0.186, p<0.001 ; 0.396, p<0.001 ;-0.328, p<0.001$, respectively) (Table 6).

\subsection{Inter and Intra-Observer Variability}

The quality control process was designed to be simple, reproducible and sustainable. Intra-observer variability was tested in 2 observers (FF, RC), who volunteered to repeat the measurement session of images in 20 randomly selected cases on two separate days. The intra-observer quality control analysis revealed an excellent ICC of 0.98 for GLS and GCS (95\% CI: 0.95 to 0.99 ) and ICC of 0.97 for HDF (95\% CI: 0.95-0.99) (all $p<0.01$ ) (Table 7).

Inter-observer variability was tested in two blinded and independent observers (FF, $\mathrm{RC}$ ). Reproducibility analyses was performed on the same set of images in 30 randomly selected cases. Inter-observer analysis showed excellent repeatability and reproducibility. ICC varies between 0.94 and 0.99 for both strain components (GCS and GLS), and 0.93-0.98 for HDF (all $p<0.01$ ) (Table 7). 
Table 7. Intra-and inter-observer variability of GLS, GCS and amplitude heart beat longitudinal HDFs.

\begin{tabular}{ccccc}
\hline Variables & ICC & \multicolumn{2}{c}{ 95\% Confidence Interval } & $p$ Value \\
\hline & & Lower Bound & Upper Bound & \\
\hline Intra-observer variability & & & 0.99 & $<0.01$ \\
\hline GLS & 0.98 & 0.96 & 0.99 & $<0.01$ \\
\hline GCS & 0.98 & 0.95 & 0.99 & $<0.01$ \\
\hline $\begin{array}{c}\text { Amplitude Heart Beat } \\
\text { Longitudinal }\end{array}$ & 0.98 & 0.95 & 0.99 & $<0.01$ \\
\hline $\begin{array}{c}\text { Inter-observer variability } \\
\text { GLS }\end{array}$ & 0.98 & 0.94 & 0.99 & $<0.01$ \\
\hline GCS & 0.98 & 0.94 & 0.98 & $<0.01$
\end{tabular}

$\overline{\text { ICC, intraclass correlation coefficient; HDFs, hemodynamic forces; GLS, global longitudinal strain; GCS, global }}$ circumferential strain.

\section{Discussion}

HDFs introduce novel information about cardiac mechanics. In this regard, looking at the dynamics of blood flow provides an alternative viewpoint to cardiac function. Here, HDFs correspond to the ultimate result of LV contraction-relaxation rhythm and play an important role in the description of cardiac function (Figures 2 and 5).

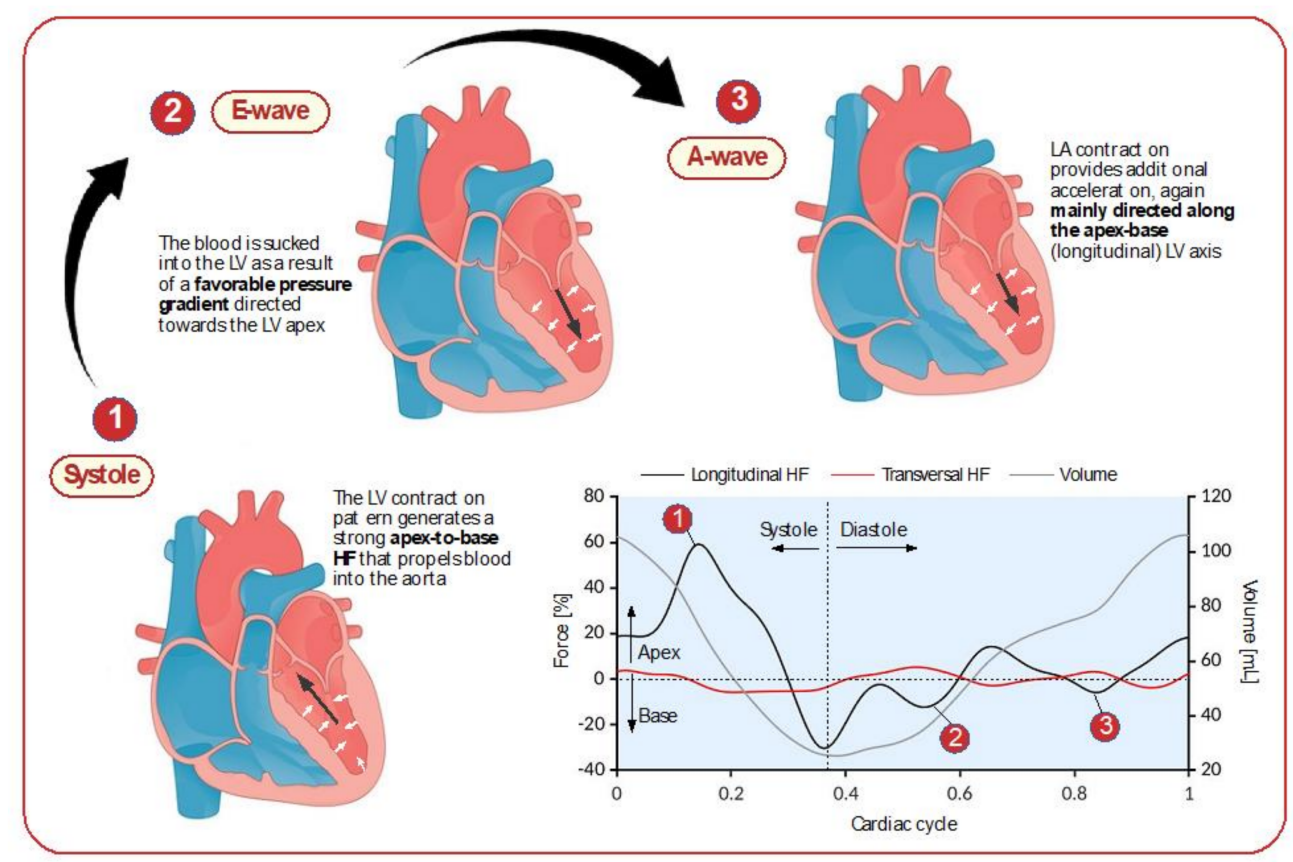

Figure 5. Representation of LV HDFs in the whole cardiac cycle. LV, left ventricular; HDFs, hemodynamic forces.

\subsection{Previous Studies}

IVPGs play an important physiological role [13] as described by several catheterization studies [30-33]. In fact, the development of IVPGs in the apex-to-based direction ensures efficient ejection of blood into the aorta during systole [34] and at early diastole (suction) represents a key factor for diastolic filling [34,35]. Unfortunately, widespread clinical applications of IVPGs have been limited by the need of invasive measurements. However, 
with the advent of blood flow imaging technologies, such as echo particle image velocimetry (Echo-PIV) and especially 4D Flow MRI, the IVPGs could be also evaluated non-invasively. The HDFs concept represents a modern approach, a global IVPG measure given by its value averaged over the entire LV volume. Preliminary studies with Echo-PIV demonstrated that HDFs lose their longitudinal alignment by alteration of LV synchrony [18]. The above result have been confirmed by 4 D Flow MRI investigations $[16,36]$ demonstrating HDFs as a clear marker of systolic efficiency. However, MRI flow imaging present a certain operational complexity and costs resulting feasible only among limited populations [37]. The availability of HDFs quantification based on STE technology allows more extensive clinical evaluations [38].

Recently, Faganello et al. [39] have applied an extension of the strain echocardiography software package in order to determine HDFs normal limits among a relatively large cohort of healthy subjects (176 subjects; age range: $16-82 ; 51 \%$ women). This study demonstrated that LV systolic longitudinal HDF and LV impulse were higher in men than in women $(16.2 \pm 5.3$ vs. $13.2 \pm 3.6 ; 25.1 \pm 7.9$ vs. $19.4 \pm 5.6$ and $20.4 \pm 7$ vs. $16.6 \pm 5.2, p<0.0001$, respectively). A weak but statistically significant decline with advancing age was also found for HDFs parameters, following the trend of GLS (all $p<0.0001)$. On the other hand, GCS and LVEF showed an increase with older age (all $p<0.0001$ ).

\subsection{Uniqueness of the Present Study}

To the best of our knowledge, this is the largest study that: (a) comprehensively assessed the full range of HDFs parameters (longitudinal and transversal) in a large cohort of healthy individuals stratified by age and sex; (b) demonstrated systolic HDFs parameters were higher in men than women, except for diastolic HDFs parameters; (c) showed HDFs longitudinal parameters were reduced in older age (GLS and LVEF did not change, while GCS increased with age); (d) revealed age, BSA, pulse pressure, heart rate and GCS were the only independent variables associated with LV longitudinal HDFs. In this regard the interesting paper by Faganello et al. [39] on a healthy population did not report the clinical and echocardiographic correlates of HDF.

Our findings suggest a physiological impact of the aging process more evident on the systolic HDFs parameters (reduced) and GCS (increased) than on GLS and LVEF. The compensatory (to preserve cardiac output) progressive increase of GCS with aging was already described in previous studies [39-41]. On the contrary, data relating to GLS and aging in healthy subjects were more controversial $[39,42,43]$. Our data showed that GLS did not decrease significantly with older age. Minor differences between the study of Faganello et al. [39] and the present study in age population ( $47 \pm 18$ vs. $43.4 \pm 14$ years, respectively) and systolic blood pressure (128 \pm 18 vs. $122 \pm 12 \mathrm{mmHg}$, respectively) could explain the differences in GLS related to age. It is likely that the minor degree of increased afterload would be insufficient to influence LV systolic function, as measured by GLS. On the other hand, the significant correlation of HDFs parameters with GCS and pulse pressure may be indicative that HDFs were more influenced by increased arterial stiffening and afterload with advancing age. These effects may increase the susceptibility of aging heart to ventricular dysfunction, suggesting the HDFs as a potential marker of earlier alterations of cardiac LV mechanics. The reference values of HDFs parameters reported in the present study were consistent with previous results, using the same strain-based HDFs technology and software [39].

\section{Limitations}

Few study limitations need to be discussed. First, our study was limited to Caucasian healthy subjects. For this reason, the clinical relevance in different races and pathologic states was not assessed. Second, the present study did not validate the accuracy of strain measurements against reference standards such as MRI. The quantitative comparison with previous evaluations with 4 D Flow MRI in a relatively smaller number of patients showed larger systolic values (present study: amplitude $=20.8 \pm 6.2$; Töger et al. 2018 [44]: $n=23$, 
amplitude $=15.0 \pm 5.0$; Arvidsson et al. 2017 [3]: $n=39$, amplitude $=13.5 \pm 6.8$ ) and substantially similar values in diastole (present study: amplitude $=8.1 \pm 2.7$; Töger et al. 2018 [44]: $n=23$, amplitude $=10.0 \pm 2.5$ ), although details of normalization were not identical. This difference may be partly imputable to imaging technology: 4D flow MRI has a lower temporal resolution that smooths out the sharp systolic acceleration especially during systole, and presents a smoother flow averaged over numerous heartbeats that cancels the sharper local flow peaks. Third, values of GLS and GCS between the different ultrasound vendors were not compared. Inter-vendor variability exists even in full-thickness strain due to the differences in the analytical algorithm. Forth, the apical approach to GCS could be less accurate because the entire circumference was not visible from the apical views. These potential pitfalls were minimized by using a triplane evaluation, commonly used in the evaluation of $\mathrm{LV}$ volumes.

\section{Conclusions}

We reported the physiologic range of LV strain and LV-HDFs parameters measured by TTE. Knowledge of age- and gender-specific reference values, for a combination of standard, mechanical and hemodynamic indices may improve the global assessment of the LV function and help to detect sub-clinical stages of LV dysfunction.

Author Contributions: All authors have drafted the work and substantively revised it. All authors have read and agreed to the published version of the manuscript.

Funding: This research did not receive any specific grant from funding agencies in the public, commercial, or not-for-profit sectors.

Institutional Review Board Statement: The study was approved by the Institution's ethics board.

Informed Consent Statement: Informed consent was obtained from all subjects involved in the study.

Data Availability Statement: The data that support the findings of this study are available from the corresponding author upon reasonable request.

Conflicts of Interest: The authors declare that there is no conflict of interest.

\section{References}

1. Yancy, C.W.; Jessup, M.; Bozkurt, B.; Butler, J.; Casey, D.E., Jr.; Drazner, M.H.; Fonarow, G.C.; Geraci, S.A.; Horwich, T.; Januzzi, J.L.; et al. 2013 ACCF/AHA guideline for the management of heart failure: A report of the American College of Cardiology Foundation/American Heart Association Task Force on Practice Guidelines. J. Am. Coll. Cardiol. 2013, 62, e147-e239. [CrossRef] [PubMed]

2. Nishimura, R.A.; Otto, C.M.; Bonow, R.O.; Carabello, B.A.; Erwin, J.P., III; Fleisher, L.A.; Jneid, H.; Mack, M.J.; McLeod, C.J.; O'Gara, P.T.; et al. 2017 AHA/ACC Focused Update of the 2014 AHA/ACC Guideline for the Management of Patients with Valvular Heart Disease: A Report of the American College of Cardiology/American Heart Association Task Force on Clinical Practice Guidelines. Circulation 2017, 135, e1159-e1195. [CrossRef]

3. Arvidsson, P.M.; Töger, J.; Carlsson, M.; Steding-Ehrenborg, K.; Pedrizzetti, G.; Heiberg, E.; Arheden, H. Left and right ventricular hemodynamic forces in healthy volunteers and elite athletes assessed with $4 \mathrm{D}$ flow magnetic resonance imaging. Am. J. Physiol. Circ. Physiol. 2017, 312, H314-H328. [CrossRef] [PubMed]

4. Voigt, J.U.; Pedrizzetti, G.; Lysyansky, P.; Marwick, T.H.; Houle, H.; Baumann, R.; Badano, L.P. Definitions for a common standard for 2Dspeckle tracking echocardiography: Consensus document of the EACVI/ASE/industry task force to standardize deformation imaging. Eur. Heart J. Cardiovasc. Imaging 2015, 28, 183-193.

5. Mignot, A.; Donal, E.; Zaroui, A.; Reant, P.; Salem, A.; Hamon, C.; Monzy, S.; Roudaut, R.; Habib, G.; Lafitte, S. Global Longitudinal Strain as a Major Predictor of Cardiac Events in Patients with Depressed Left Ventricular Function: A Multicenter Study. J. Am. Soc. Echocardiogr. 2010, 23, 1019-1024. [CrossRef] [PubMed]

6. $\quad$ Ersbøll, M.; Valeur, N.; Mogensen, U.M.; Andersen, M.J.; Møller, J.E.; Velazquez, E.J.; Hassager, C.; Søgaard, P.; Køber, L. Prediction of All-Cause Mortality and Heart Failure Admissions from Global Left Ventricular Longitudinal Strain in Patients with Acute Myocardial Infarction and Preserved Left Ventricular Ejection Fraction. J. Am. Coll. Cardiol. 2013, 61, 2365-2373. [CrossRef] [PubMed]

7. Pedrizzetti, G.; Claus, P.; Kilner, P.J.; Nagel, E. Principles of cardiovascular magnetic resonance feature tracking and echocardiographic speckle tracking for informed clinical use. J. Cardiovasc. Magn. Reson. 2016, 18, 1-12. [CrossRef] [PubMed]

8. Maier, S.E.; Fischer, S.E.; McKinnon, G.C.; Hess, O.M.; Krayenbuehl, H.P.; Boesiger, P. Evaluation of left ventricular segmental wall motion in hypertrophic cardiomyopathy with myocardial tagging. Circulation 1992, 86, 1919-1928. [CrossRef] [PubMed] 
9. Yeon, S.B.; Reichek, N.; Tallant, B.A.; Lima, J.A.; Calhoun, L.P.; Clark, N.R.; Hoffman, E.; Ho, K.; Axel, L. Validation of in vivo myocardial strain measurement by magnetic resonance tagging with sonomicrometry. J. Am. Coll. Cardiol. 2001, 38, 555-561. [CrossRef]

10. Courtois, M.; Kovácsjr, S.J.; Ludbrook, P.A. Transmitral pressure-flow velocity relation. Importance of regional pressure gradients in the left ventricle during diastole. Circulation 1988, 78, 661-671. [CrossRef]

11. Firstenberg, M.S.; Vandervoort, P.M.; Greenberg, N.L.; Smedira, N.G.; McCarthy, P.M.; Garcia, M.J.; Thomas, J.D. Noninvasive estimation of transmitral pressure drop across the normal mitral valve in humans: Importance of convective and inertial forces during left ventricular filling. J. Am. Coll. Cardiol. 2000, 36, 1942-1949. [CrossRef] [PubMed]

12. Greenberg, N.L.; Vandervoort, P.M.; Firstenberg, M.S.; Garcia, M.J.; Thomas, J.D. Estimation of diastolic intraventricular pressure gradients by Doppler M-mode echocardiography. Am. J. Physiol. Circ. Physiol. 2001, 280, H2507-H2515. [CrossRef]

13. Guerra, M.; Silva, C.B.; Amorim, M.J.; Moura, C.; Bastos, P.; Leite-Moreira, A.F. Intraventricular Pressure Gradients in Heart Failure. Physiol. Res. 2013, 62, 479-487. [CrossRef] [PubMed]

14. Domenichini, F.; Pedrizzetti, G. Hemodynamic forces in a model left ventricle. Phys. Rev. Fluids 2016, 1, 083201. [CrossRef]

15. Pedrizzetti, G.; Martiniello, A.R.; Bianchi, V.; D'Onofrio, A.; Caso, P.; Tonti, G. Cardiac fluid dynamics anticipates heart adaptation. J. Biomech. 2015, 48, 388-391. [CrossRef]

16. Arvidsson, P.M.; Töger, J.; Pedrizzetti, G.; Heiberg, E.; Borgquist, R.; Carlsson, M.; Arheden, H. Hemodynamic forces using four-dimensional flow MRI: An independent biomarker of cardiac function in heart failure with left ventricular dyssynchrony? Am. J. Physiol. Circ. Physiol. 2018, 315, H1627-H1639. [CrossRef] [PubMed]

17. Eriksson, J.; Bolger, A.F.; Ebbers, T.; Carlhäll, C. Assessment of left ventricular hemodynamic forces in healthy subjects and patients with dilated cardiomyopathy using 4D flow MRI. Physiol. Rep. 2016, 4, e12685. [CrossRef] [PubMed]

18. Pedrizzetti, G.; Martiniello, A.R.; Bianchi, V.; D'Onofrio, A.; Caso, P.; Tonti, G. Changes in electrical activation modify the orientation of left ventricular flow momentum: Novel observations using echocardiographic particle image velocimetry. Eur. Hear. J. Cardiovasc. Imaging 2015, 17, 203-209. [CrossRef] [PubMed]

19. Lapinskas, T.; Pedrizzetti, G.; Stoiber, L.; Düngen, H.-D.; Edelmann, F.; Pieske, B.; Kelle, S. The Intraventricular Hemodynamic Forces Estimated Using Routine CMR Cine Images. JACC Cardiovasc. Imaging 2019, 12, 377-379. [CrossRef] [PubMed]

20. Ferro, M.D.; De Paris, V.; Collia, D.; Stolfo, D.; Caiffa, T.; Barbati, G.; Korcova, R.; Pinamonti, B.; Zovatto, L.; Zecchin, M.; et al. Left Ventricular Response to Cardiac Resynchronization Therapy: Insights from Hemodynamic Forces Computed by Speckle Tracking. Front. Cardiovasc. Med. 2019, 6, 59. [CrossRef]

21. Pedrizzetti, G.; Arvidsson, P.M.; Töger, J.; Borgquist, R.; Domenichini, F.; Arheden, H.; Heiberg, E. On estimating intraventricular hemodynamic forces from endocardial dynamics: A comparative study with 4D flow MRI. J. Biomech. 2017, 60, 203-210. [CrossRef] [PubMed]

22. Pedrizzetti, G.; Tanacli, R.; Lapinskas, T.; Zovatto, L.; Pieske, B.; Tonti, G.; Kelle, S. Integration between volumetric change and strain for describing the global mechanical function of the left ventricle. Med. Eng. Phys. 2019, 74, 65-72. [CrossRef] [PubMed]

23. Ferrara, F.; Rudski, L.G.; Vriz, O.; Gargani, L.; Afilalo, J.; D’Andrea, A.; D'Alto, M.; Marra, A.M.; Acri, E.; Stanziola, A.A.; et al. Physiologic correlates of tricuspid annular plane systolic excursion in 1168 healthy subjects. Int. J. Cardiol. 2016, 223, 736-743. [CrossRef]

24. Ferrara, F.; Gargani, L.; Ruohonen, S.; Vriz, O.; Scalese, M.; Russo, V.; Marra, A.M.; Stanziola, A.A.; Cittadini, A.; D’Andrea, A.; et al. Reference values and correlates of right atrial volume in healthy adults by two-dimensional echocardiography. Echocardiography 2018, 35, 1097-1107. [CrossRef] [PubMed]

25. Lang, R.M.; Badano, L.P.; Mor-Avi, V.; Afilalo, J.; Armstrong, A.; Ernande, L.; Flachskampf, F.A.; Foster, E.; Goldstein, S.A.; Kuznetsova, T.; et al. Recommendations for Cardiac Chamber Quantification by Echocardiography in Adults: An Update from the American Society of Echocardiography and the European Association of Cardiovascular Imaging. J. Am. Soc. Echocardiogr. 2015, 28, 1-39.e14. [CrossRef] [PubMed]

26. Nagueh, S.F.; Smiseth, O.A.; Appleton, C.P.; Byrd, B.F., III; Dokainish, H.; Edvardsen, T.; Flachskampf, F.A.; Gillebert, T.C.; Klein, A.L.; Lancellotti, P.; et al. Recommendations for the Evaluation of Left Ventricular Diastolic Function by Echocardiography: An Update from the American Society of Echocardiography and the European Association of Cardiovascular Imaging. J. Am. Soc. Echocardiogr. 2016, 29, 277-314. [CrossRef] [PubMed]

27. Rudski, L.G.; Lai, W.W.; Afilalo, J.; Hua, L.; Handschumacher, M.; Chandrasekaran, K.; Solomon, S.D.; Louie, E.K.; Schiller, N.B. Guidelines for the Echocardiographic Assessment of the Right Heart in Adults: A Report from the American Society of Echocardiography: Endorsed by the European Association of Echocardiography, a registered branch of the European Society of Cardiology, and the Canadian Society of Echocardiography. J. Am. Soc. Echocardiogr. 2010, 23, 685-713. [CrossRef] [PubMed]

28. Mor-Avi, V.; Lang, R.M.; Badano, L.P.; Belohlavek, M.; Cardim, N.M.; Derumeaux, G.; Galderisi, M.; Marwick, T.; Nagueh, S.F.; Sengupta, P.P.; et al. Current and Evolving Echocardiographic Techniques for the Quantitative Evaluation of Cardiac Mechanics: ASE/EAE Consensus Statement on Methodology and Indications endorsed by the Japanese Society of Echocardiography. J. Am. Soc. Echocardiogr. 2011, 24, 277-313. [CrossRef] [PubMed]

29. Rushmer, R.F.; Harding, D.; Baker, D.; Watson, N. Initial Ventricular Impulse. Circulation 1964, 29, 268-283. [CrossRef] [PubMed]

30. Pasipoularides, A.; Murgo, J.P.; Miller, J.W.; Craig, W.E. Nonobstructive left ventricular ejection pressure gradients in man. Circ. Res. 1987, 61, 220-227. [CrossRef] [PubMed] 
31. Brutsaert, D.L. Nonuniformity: A physiologic modulator of contraction and relaxation of the normal heart. J. Am. Coll. Cardiol. 1987, 9, 341-348. [CrossRef]

32. Butler, C.K.; Wong, A.Y.K.; Armour, J.A. Systolic pressure gradients between the wall of the left ventricle, the left ventricular chamber, and the aorta during positive inotropic states: Implications for left ventricular efficiency. Can. J. Physiol. Pharmacol. 1988, 66, 873-879. [CrossRef] [PubMed]

33. Courtois, M.; Kovács, S.J.; Ludbrook, P.A. Physiological early diastolic intraventricular pressure gradient is lost during acute myocardial ischemia. Circulation 1990, 81, 1688-1696. [CrossRef] [PubMed]

34. Guerra, M.; Amorim, M.J.; Brás-Silva, C.; Leite-Moreira, A.F. Intraventricular pressure gradients throughout the cardiac cycle: Effects of ischaemia and modulation by afterload. Exp. Physiol. 2013, 98, 149-160. [CrossRef]

35. Smiseth, O.A.; Steine, K.; Sandbæk, G.; Stugaard, M.; Gjølberg, T.Ø. Mechanics of intraventricular filling: Study of LV early diastolic pressure gradients and flow velocities. Am. J. Physiol. Circ. Physiol. 1998, 275, H1062-H1069. [CrossRef]

36. Eriksson, J.; Zajac, J.; Alehagen, U.; Bolger, A.F.; Ebbers, T.; Carlhäll, C.-J. Left ventricular hemodynamic forces as a marker of mechanical dyssynchrony in heart failure patients with left bundle branch block. Sci. Rep. 2017, 7, 2971. [CrossRef] [PubMed]

37. Leiner, T.; Bogaert, J.; Friedrich, M.G.; Mohiaddin, R.; Muthurangu, V.; Myerson, S.; Powell, A.J.; Raman, S.V.; Pennell, D.J. SCMR Position Paper (2020) on clinical indications for cardiovascular magnetic resonance. J. Cardiovasc. Magn. Reson. 2020, $22,1-37$. [CrossRef]

38. Ferro, M.D.; Stolfo, D.; De Paris, V.; Lesizza, P.; Korcova, R.; Collia, D.; Tonti, G.; Sinagra, G.; Pedrizzetti, G. Cardiac fluid dynamics meets deformation imaging. Cardiovasc. Ultrasound 2018, 16, 4. [CrossRef] [PubMed]

39. Faganello, G.; Collia, D.; Furlotti, S.; Pagura, L.; Zaccari, M.; Pedrizzetti, G.; Di Lenarda, A. A new integrated approach to cardiac mechanics: Reference values for normal left ventricle. Int. J. Cardiovasc. Imaging 2020, 36, 2173-2185. [CrossRef] [PubMed]

40. Muraru, D.; Cucchini, U.; Mihăilă, S.; Miglioranza, M.H.; Aruta, P.; Cavalli, G.; Cecchetto, A.; Padayattil-Josè, S.; Peluso, D.; Iliceto, S.; et al. Left Ventricular Myocardial Strain by Three-Dimensional Speckle-Tracking Echocardiography in Healthy Subjects: Reference Values and Analysis of Their Physiologic and Technical Determinants. J. Am. Soc. Echocardiogr. 2014, 27, 858-871.e1. [CrossRef] [PubMed]

41. Alcidi, G.M.; Esposito, R.; Evola, V.; Santoro, C.; Lembo, M.; Sorrentino, R.; Iudice, F.L.; Borgia, F.; Novo, G.; Trimarco, B.; et al. Normal reference values of multilayer longitudinal strain according to age decades in a healthy population: A single-centre experience. Eur. Hear. J. Cardiovasc. Imaging 2017, 19, 1390-1396. [CrossRef]

42. Marwick, T.H.; Leano, R.L.; Brown, J.; Sun, J.-P.; Hoffmann, R.; Lysyansky, P.; Becker, M.; Thomas, J.D. Myocardial Strain Measurement With 2-Dimensional Speckle-Tracking Echocardiography: Definition of normal range. JACC Cardiovasc. Imaging 2009, 2, 80-84. [CrossRef] [PubMed]

43. Sugimoto, T.; Dulgheru, R.; Bernard, C.; Ilardi, F.; Contu, L.; Addetia, K.; Caballero, L.; Akhaladze, N.; Athanassopoulos, G.D.; Barone, D.; et al. Echocardiographic reference ranges for normal left ventricular 2D strain: Results from the EACVI NORRE study. Eur. Hear. J. Cardiovasc. Imaging 2017, 18, 833-840. [CrossRef]

44. Töger, J.; Arvidsson, P.M.; Bock, J.; Kanski, M.; Pedrizzetti, G.; Carlsson, M.; Arheden, H.; Heiberg, E. Hemodynamic forces in the left and right ventricles of the human heart using 4D flow magnetic resonance imaging: Phantom validation, reproducibility, sensitivity to respiratory gating and free analysis software. PLoS ONE 2018, 13, e0195597. [CrossRef] [PubMed] 